\title{
Residential proximity to major roads and adverse birth outcomes: a hospital-based study
}

${\text { Takashi Yorifuji }{ }^{*} \text {, Hiroo Naruse }}^{2}$, Saori Kashima ${ }^{3}$, Soshi Takao ${ }^{4}$, Takeshi Murakoshi², Hiroyuki Doi ${ }^{4}$ and Ichiro Kawachi ${ }^{5}$

\begin{abstract}
Background: Exposure to air pollution has been demonstrated to increase the risk of preterm birth and low birth weight (LBW). Although evidence has accumulated on characteristics associated with increased risk of air pollutionrelated health effects, most studies have been conducted in the adult population and evidence on reproductive outcomes is limited. We examined whether socio-economic position (SEP) and parental characteristics (parental behavior and co-morbidity) modified the relationship between air pollution and adverse birth outcomes.

Methods: Data were extracted from a perinatal hospital database based in Shizuoka, Japan. We restricted the analysis to mothers who delivered live-born single births from January 1997 to December $2010(n=16,615)$. Each birth was assigned proximity to major roads. Multivariate adjusted odds ratios (ORs) and their $95 \%$ confidence intervals (Cls) were estimated for the outcomes of preterm birth and term LBW. We stratified subjects by individual/ area-level SEP and parental characteristics. We then measured interactions on the additive scale between the respective factors and exposure.
\end{abstract}

Results: Lower SEP at both individual and area levels was associated with the increased occurrence of adverse birth outcomes. Living within $200 \mathrm{~m}$ from a major road increased the risk of preterm birth by 1.5 times (95\% Cl: 1.3-1.9) and LBW by 1.2 times (95\% Cl: 0.9-1.6). Mothers with lower individual SEP defined by household occupation experienced higher ORs for term LBW (OR $=3.1,95 \% \mathrm{Cl}$ : 1.2-8.2) compared with those with higher individual SEP. In contrast, mothers who lived in the highest area-level SEP region (i.e., affluent areas) showed slightly higher point estimates compared with those who lived in middle or poor areas. In addition, maternal diabetic and hypertensive status modified the association between proximity and preterm birth, while maternal smoking status modified the association between proximity and term LBW.

Conclusions: The present study demonstrated that air pollution is an independent risk factor for adverse birth outcomes. Mothers with lower individual SEP and mothers living in higher SEP region may be susceptible to the adverse effect of air pollution. Maternal diabetic, hypertensive, and smoking status may also increase susceptibility to this air pollution-related health effect.

Keywords: Air pollution, Diabetes mellitus, Geographic Information System, Hypertension, Low birth weight, Pregnancy outcomes, Preterm birth, Socio-economic position, Smoking

\footnotetext{
* Correspondence: yorichan@md.okayama-u.ac.jp

'Department of Human Ecology, Okayama University Graduate School of Environmental and Life Science, 1-1-1 Tsushima-naka, Kita-ku, Okayama 700-8530, Japan

Full list of author information is available at the end of the article
} 


\section{Background}

Evidence has accumulated on the association between air pollution and adverse birth outcomes, such as preterm birth or low birth weight (LBW) [1-4]. Indeed, recent systematic reviews and original studies have indicated positive associations between various air pollution indicators (e.g., gaseous pollutants, particulate matter, and air pollution surrogates) and birth outcomes [5-8].

Recently, several studies have attempted to identify characteristics associated with increased risk of air pollutionrelated health effects, e.g. age, preexisting cardiovascular disease, diabetes, and low socio-economic position (SEP) $[9,10]$. However, most studies were conducted in the adult population, and evidence concerning reproductive outcomes is limited and potentially conflicting [11].

Because SEP is a robust predictor of health outcomes, it has been questioned whether SEP is a confounder or an effect modifier of the association between air pollution and adverse health outcomes [12]. A growing number of studies have therefore sought to examine the simultaneous impacts of SEP and air pollution, although most studies considered SEP a confounder. Evidence concerning group/area-level SEP modification is somewhat conflicting [13-17], but many studies have observed effect modification by individual SEP, i.e. lower SEP individuals may be more susceptible to adverse effects of air pollution, which may in turn be related to underlying vulnerability (co-morbidity or adverse health behavior such as smoking) [18-21].

In the field of air pollution and reproductive epidemiology, four studies have examined how SEP potentially modified the relationships between air pollution and adverse birth outcomes [22-25]. Three of these used a distance-based exposure index as the air pollution indicator, but reported potentially conflicting results. Two studies in California, USA, observed increased effect estimates for preterm birth and LBW in low SEP census areas [23,24], while a study in Canada demonstrated the opposite result, i.e. increased pollution-related effects for preterm birth, LBW, and small-for-gestational-age birth in subjects who had higher SEP both at the individual and group/district level [22]. Another study in Korea, which used particulate matter concentration $\left(\mathrm{PM}_{10}\right)$ as the exposure index, found a higher effect estimate for preterm birth in low SEP regions [25].

Moreover, few studies have evaluated how parental characteristics (except SEP characteristics) modify the association between air pollution and reproductive outcomes, although the findings may provide important insights for possible mechanisms [3]. One study in New Jersey, USA, observed increased effect estimates for small-for-gestational-age birth among pregnant women with pregnancy complications (i.e. placental abruption and premature rupture of the membrane) [26].
In the present study, we therefore used a hospitalbased perinatal database to evaluate how SEP at both individual and group/area levels and parental characteristics potentially modify the relationship between air pollution and adverse birth outcomes (preterm birth and term LBW).

\section{Methods \\ Participants}

Data were extracted from the perinatal database maintained at the Seirei Hamamatsu General Hospital, Shizuoka, Japan since January 1997. The hospital is the main perinatal medical center in the western part of Shizuoka prefecture (west of Tokyo). The hospital reported 1582 new live births in 2010, and approximately one-eighth of the babies born in the western part of Shizuoka were born in this hospital [8]. The database contains information from all mothers admitted to the department of obstetrics in the hospital ( $\mathrm{n}=21,855$ from 1997 to 2010). In this study, we restricted analysis to live-born single births delivered from January 1997 to December 2010. We assumed that babies with an Apgar score of $>1$ one minute after birth were live-born births. We thus defined the eligibility criteria for inclusion in this study as follows: single births, babies whose Apgar score was $>1$ one minute after birth, babies who had birth weight data, and deliveries after 22 weeks gestational age. We retrieved 19,218 births from the database (Figure 1). Details of the methodology used in the current study have been published elsewhere [8,27].

The availability of residential information at delivery was a prerequisite for inclusion in the study because we used proximity to major roads as an index for air pollution exposure; as a result of this criterion we excluded 206 births. Furthermore, since the hospital is located in the western part of Shizuoka prefecture, we restricted births to those whose mothers lived in the western part of Shizuoka prefecture, because mothers who lived in central or eastern parts were likely to have returned to their parents' home during pregnancy to give birth (a Japanese tradition). However, we could not obtain information regarding maternal movement. When we adopted term LBW as a health outcome, we further restricted the analysis to mothers who delivered term births (born at 37 or more weeks of gestation). Our final set of participants included 16,615 births for preterm birth and 14,836 births for term LBW analyses (Figure 1).

\section{Exposure data}

We used mothers' residential proximity to major roads, which was defined according to the amount of traffic, as an index for air pollution exposure. First, we identified the exact residential address at delivery for each birth and measured proximity to major roads for all available 


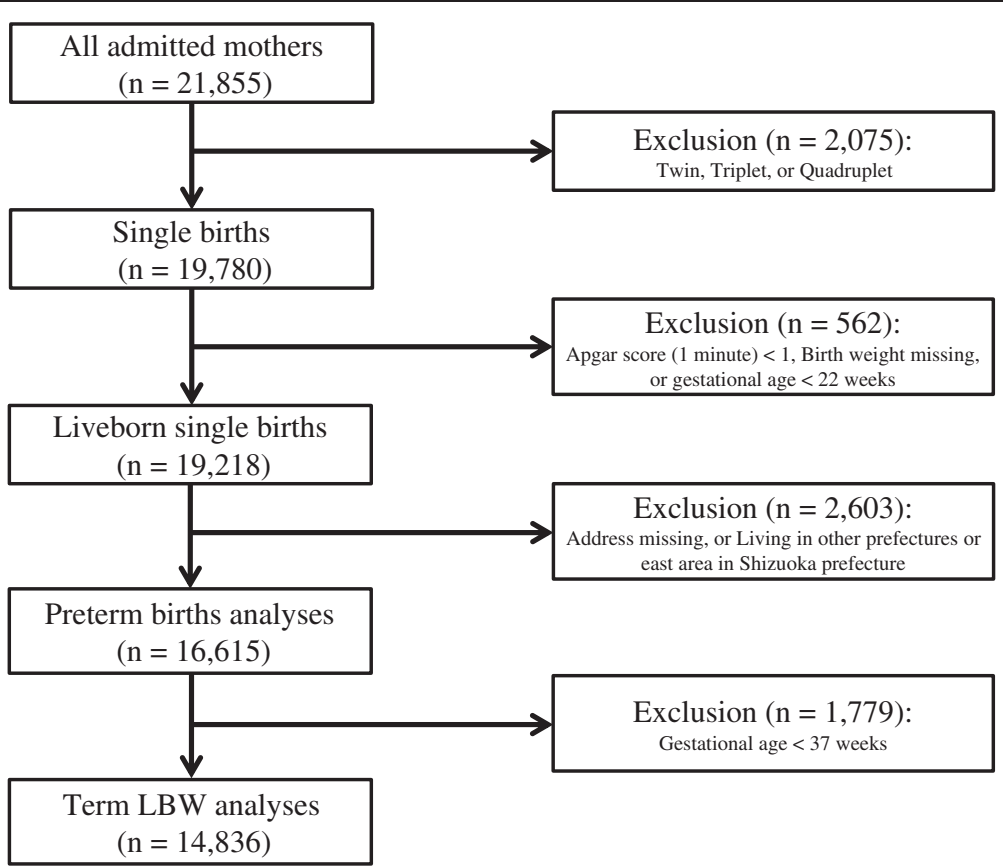

Figure 1 Selection of eligible births. When term low birth weight (LBW), i.e., birth weight $<2500 \mathrm{~g}$, was adopted as the health outcome, we restricted analyses to mothers who delivered term births (born at 37 or more completed weeks of gestation).

mothers' addresses. We categorized proximity according to the following groups $(\leq 200 \mathrm{~m} ;>200 \mathrm{~m})$ based on previous epidemiological studies [8,27-29] and exposure assessment studies showing exponential decay in exposure with increasing distance from major roads [30,31]. We also employed an alternative trichotomized exposure indictor $(\leq 50,50-200,>200 \mathrm{~m})$ to examine a possible dose-response relationship between proximity to major roads and adverse outcomes.

Major roads were defined as those having total vehicle counts greater than 50,000 per 24 hours on a weekday [32,33]. Road type and traffic volume data were obtained from the 2005 Road Traffic Census conducted by the Road Bureau of the Ministry of Land, Infrastructure, Transport, and Tourism. The major roads defined in this study corresponded almost exactly with the existing expressways or primary national highways. All geographic variables were collected by the Geographic Information System (GIS) software ArcGIS (ESRI Japan Inc., version 9.3).

\section{Outcome data}

We examined two adverse birth outcomes: preterm birth and term LBW. Preterm births were defined as births less than 37 weeks gestational age. Gestational ages were measured based on the last menstrual period, and mostly confirmed or corrected by ultrasound measurements at approximately 10 weeks gestational age. Term LBW was defined as birth weight $<2500 \mathrm{~g}$ among term newborns.

\section{Individual/area-level SEP and personal characteristics}

We retrieved information about individual characteristics from the perinatal database. Individual information was obtained from mothers by trained obstetricians or midwives at the time of prenatal checkup when the expected delivery date was confirmed, and added or corrected during admission. Occupation of the mother or father (whichever was higher) was used as our measure of individual SEP. Although occupation was available in five categories (professional workers; employees; selfemployed workers; part-time workers; unemployed and not active in the labor force including housewives), we combined the last three categories because of limited numbers in the last two categories.

We also extracted the following personal characteristics: maternal age, maternal smoking (never smoked; exsmoker including mothers who quit smoking during pregnancy; current-smoker), maternal alcohol consumption (drinker; non-drinker), paternal smoking (never smoked; ex- or current-smoker), maternal obesity (before pregnancy), maternal past history of diabetes, and maternal past history of hypertension. Maternal obesity (before pregnancy) was defined as mothers whose body mass index (BMI) was more than 25. BMI was calculated as body weight before pregnancy $(\mathrm{kg})$ divided by height squared $\left(\mathrm{m}^{2}\right)$.

Area-level SEP (at the district level) was measured as the proportion of professional workers and the proportion of production or transportation workers over 15 years of 
age in the corresponding census region where the mothers lived. Data were obtained from the 2000 national census. The study area included 1872 census regions. In the analyses examining effect modification by area-level SEP, the SEP level was tertiled as previous studies used trichotomized categories of regional SEP [23,25].

\section{Data analyses}

First, we calculated the proportions of preterm births and term LBW according to air pollution exposure category $(\leq 200 \mathrm{~m} ;>200 \mathrm{~m})$, personal characteristics, and individual/area-level SEP. We then examined the distribution of individual/area-level SEP and personal characteristics separated by proximity to major roads.

We next estimated the multivariate adjusted odds ratios (ORs) for preterm birth or term LBW according to major roads using a logistic regression model. We first obtained crude ORs (Model 1) and then adjusted for maternal age, newborn's sex, and personal characteristics that could be considered as potential confounders (Model 2) as follows: household occupation (professionals; employees; self-employed/part-time workers/ unemployed), maternal smoking (never smoked; exsmoker; current-smoker), maternal alcohol consumption (drinker; non-drinker), paternal smoking (ex- or currentsmoker; non-smoker), and maternal BMI. We further adjusted for individual SEP (Model 3). Finally, we additionally adjusted for area-level SEP (Model 4), i.e. the proportion of professional workers in the corresponding census. Gestational age was also included in all models in the analyses for LBW. Maternal BMI, the proportion of professional workers, and gestational age were treated as continuous variables. Maternal age was entered as a linear and quadratic term into the models because a U-shaped association was expected between maternal age and adverse birth outcomes.

We also employed the alternative trichotomized exposure indictor $(\leq 50,50-200,>200 \mathrm{~m})$ instead of the simple dichotomization $(\leq 200 \mathrm{~m} ;>200 \mathrm{~m})$ and repeated the analyses.

To examine effect modification by individual/arealevel SEP and parental characteristics, we stratified the subjects by individual/area-level SEP and parental characteristics and applied the final fully-adjusted logistic models (i.e., maternal age, newborn's sex, personal characteristics, and individual/area-level SEP). Each variable was excluded when the subjects were stratified by the corresponding variable. We then measured interactions on the additive scale between the respective factors and exposure. We used Excel (Microsoft Corporation, Redmond, WA, USA) spreadsheets provided by Knol and VanderWeele [34] and calculated the proportion attributable to the interaction (AP), the proportion of disease among those with both exposures that is attributable to their interaction [35]. In the absence of interaction, AP equals 0 . $\mathrm{AP}>0$ means positive interaction or more than additivity and $\mathrm{AP}<0$ means negative interaction or less than additivity.

All confidence intervals (CIs) were estimated at the 95\% level. The PASW software package (Version $18.0 \mathrm{~J}$, SPSS Japan Inc., Tokyo, Japan) was used for statistical analyses. Approval for this study was obtained from the Institutional Review Board of Seirei Hamamatsu General Hospital and Okayama University (No 498).

\section{Results}

Proportions of preterm births and term LBW according to demographic characteristics are shown in Table 1. Preterm births and LBW were observed more often in areas closer to major roads. Additionally, younger and older mothers tended to experience more adverse birth outcomes, especially for term LBW. Regarding SEP variables, as expected, mothers with higher individual SEP (defined by household occupation) and mothers who lived in higher area level SEP regions tended to have fewer preterm births. Furthermore, while maternal smoking was associated with both outcomes, maternal obesity was associated with an increased risk of preterm birth, but decreased risk of term LBW.

In Table 2, the number and percentage of individual/ area-level SEP and personal characteristics separated by proximity to major roads are shown. Mothers whose household occupation was professional and mothers who lived in affluent areas had a tendency to live further from major roads. The correlation between individual and area-level SEP is shown in Table 3, and indicates that mothers whose household occupation was professional tended to live in affluent areas.

Table 4 shows the adjusted ORs for the associations of proximity to major roads with preterm birth and term LBW. Although we adjusted for individual SEP (Model 3) and for both individual/area-level SEP variables simultaneously (Model 4), this did not substantially change the point estimates. When we adjusted for both individual/ area-level SEP variables simultaneously (Model 4), we found positive associations between proximity to major roads and preterm birth and term LBW. Specifically, living within $200 \mathrm{~m}$ of a major road increased the risk of preterm birth by 1.5 times (95\% CI: $1.3-1.9$ ) and LBW by 1.2 times (95\% CI: 0.9-1.6). Dose-response relationships between proximity to major roads and adverse outcomes were observed when we used the trichotomized exposure indictor.

Although none of the additive interaction terms between air pollution and individual/area-level SEP were statistically significant, some tendencies were observed in the stratified analyses by individual/area-level SEP (Table 5). Mothers with lower individual SEP, i.e., 
Table 1 Proportions of preterm births and term low birth weight by characteristics of parents, newborns, and census region

\begin{tabular}{cccc} 
Births & PTB & Term births & Term LBW \\
$\mathrm{n}=16,615$ & $\mathrm{n}(\%) \dagger$ & $\mathrm{n}=14,836$ & $\mathrm{n}(\%) \dagger$ \\
\hline
\end{tabular}

Parental variables

Proximity to major roads

$$
\begin{aligned}
& \leq 200 \mathrm{~m} \\
& >200 \mathrm{~m}
\end{aligned}
$$

Maternal age

$<20$

20-34

$\geq 35$

Household occupation

Professional workers

Employees

Self-employed/Part-time workers/Unemployed

Maternal smoking

Never smoked

Ex- or current-smoker

Maternal alcohol consumption

$$
\text { Non-drinker }
$$

Drinker

Paternal smoking

Never smoked

Ex or current-smoker

Maternal obesity

Not obese

Obese

Maternal diabetes

No diabetes

Diabetes

Maternal hypertension

No hypertension

Hypertension

\section{Newborn variables}

Sex

Male

Female

Parity

First birth

Second birth

More than third birth

Birth year

1997-2001

2002-2005

2006-2010
953

15662

2096

11663

2854

1854

13070

952

15545

877

15674

757

8650

7152

15215

1348

15983

617

15707

893

8571

8001

9028

5686

1889

5959

4630

6026
149 (15.6)

$1630(10.4)$

236 (11.3)

$1216(10.4)$

$327(11.5)$

$143(7.7)$

1408 (10.8)

106 (11.1)

1607 (10.3)

145 (16.5)

$1672(10.7)$

$82(10.8)$

$874(10.1)$

774 (10.8)

1574 (10.3)

183 (13.6)

1704 (10.7)

$72(11.7)$

1672 (10.6)

104 (11.6)

1006 (11.7)

770 (9.6)

928 (10.3)

618 (10.9)

232 (12.3)

$568(9.5)$

539 (11.6)

$672(11.2)$
804

14032

1860

10447

2527

1711

11662

846

13938

732

14002

675

7776

6378

13641

1165

14279

545

14035

789

1149 (8.2)

74 (9.4)

1149 (8.4)

$72(6.2)$

$1180(8.3)$

$44(8.1)$

490 (6.5)

730 (10.1)

7231

748 (9.2)

349 (6.9)

$127(7.7)$

1657

$425(7.9)$

356 (8.7)

$444(8.3)$ 


\begin{tabular}{|c|c|c|c|c|}
\hline \multicolumn{5}{|c|}{ Census regions level variables } \\
\hline \multicolumn{5}{|c|}{ Proportion of professional workers } \\
\hline Q1 (13.0-33.8\%) (affluent) & 5453 & $514(9.4)$ & 4939 & $342(6.9)$ \\
\hline Q2 (10.0-13.0\%) (middle) & 5524 & $543(9.8)$ & 4981 & $441(8.9)$ \\
\hline Q3 (0-10.0\%) (poor) & 5628 & $720(12.8)$ & 4908 & $442(9.0)$ \\
\hline \multicolumn{5}{|c|}{ Proportion of production or transportation workers } \\
\hline Q1 (0-37.9\%) (affluent) & 5406 & $486(9.0)$ & 4920 & $374(7.6)$ \\
\hline Q2 (37.9-45.2\%) (middle) & 5589 & $575(10.3)$ & 5014 & $414(8.3)$ \\
\hline Q3 (45.2-86.3\%) (poor) & 5610 & $716(12.8)$ & 4894 & $437(8.9)$ \\
\hline
\end{tabular}

†Proportions of PTBs were calculated by dividing the number of PTBs by total births in the corresponding category. Proportions of LBW births were calculated by dividing the number of term LBW by total term births in the corresponding category.

PTB; preterm birth, LBW; low birth weight.

household occupation "Self-employed/Part-time workers/ Unemployed", experienced higher ORs for the association between proximity and term $\mathrm{LBW}(\mathrm{OR}=3.1,95 \% \mathrm{CI}$ : 1.2-8.2) compared with other household occupation categories. In contrast, in the analyses stratified by area-level SEP, mothers who lived in the highest area-level SEP region (i.e., affluent areas) showed slightly higher point estimates for the associations between proximity and adverse birth outcomes compared with those who lived in middle or poor areas. For example, the OR in affluent areas defined by proportion of production or transportation workers was 2.5 (95\% CI: 1.1-5.5) for term LBW.

Regarding stratified analyses by parental characteristics, mothers who reported a past history of diabetes and hypertension experienced a higher OR for the association between proximity and preterm birth (Table 5): e.g., $\mathrm{OR}=4.4$ (95\% CI: $1.9-10)$ for those with diabetes and $\mathrm{OR}=1.5$ for those without diabetes (95\% CI: 1.21.8), and the corresponding AP was 0.6. Thus, it could be argued that $60 \%$ of preterm births among those with both exposure conditions (living within $200 \mathrm{~m}$ from major roads and diabetes) were attributable to their interaction. In contrast, ex- or currently smoking mothers experienced a higher OR for the association between proximity and term LBW.

\section{Discussion}

In this study, we evaluated how SEP at both individual and group/area-levels and parental characteristics modified the relationship between air pollution and adverse birth outcomes (preterm birth and term LBW), using proximity to major roads as an exposure indicator. We observed that mothers from lower individual SEP, defined by household occupation, had higher effect estimates for term LBW compared with mothers with higher individual SEP. In contrast, mothers from higher area-level SEP regions tended to have higher effect estimates for both preterm birth and term LBW compared with mothers from lower area-level SEP regions. In addition, maternal diabetic, hypertensive, and smoking status modified the association between proximity and birth outcomes.

There is a lack of studies on this topic from Asian countries. Extrapolation from studies conducted in different areas may be inappropriate because of differences in pollution characteristics, health care systems, meaning of SEP indicators, study designs, and demographics of the population.

The findings of this study are consistent with recent studies suggesting that air pollution exposure increases the risk of preterm birth and term LBW [6,7]. Our study additionally supports the finding that lower individual or area-level SEP is associated with adverse birth outcomes [36,37], even in an egalitarian country like Japan [38].

In the analyses stratified by SEP, although not statistically significant, mothers with lower individual SEP showed susceptibility to air pollution as expected, especially in the "Self-employed/Part-time workers/ Unemployed" occupational category. This finding is consistent with previous air pollution studies examining cardiopulmonary outcomes among the adult population. These studies showed susceptibility associated with lower education or income at the individual level [18-21]. In contrast, mothers who lived in higher area-level SEP regions tended to have greater effect estimates for adverse birth outcomes stemming from air pollution exposure. This finding is similar to the study in Canada, which showed stronger effects in higher area-level SEP neighborhoods [22], and contradicts some previous studies showing increased susceptibility in lower SEP areas [23-25].

Moreover, we found that maternal diabetic and hypertensive status modified the relationship between air pollution and preterm birth. This finding is consistent with previous air pollution studies in adult settings, which showed that air pollution-related health effects were stronger among diabetic or hypertensive patients $[9,10,39]$. 
Table 2 Number and percentages of individual/area-level SEP and personal characteristics by proximity to major roads $(\leq 200 \mathrm{~m} ;>200 \mathrm{~m})(\mathrm{n}=\mathbf{1 6 , 6 1 5})$

\begin{tabular}{|c|c|c|}
\hline & \multicolumn{2}{|c|}{ Proximity to major roads } \\
\hline & $\leq \mathbf{2 0 0 \mathrm { m }}$ & $>200 \mathrm{~m}$ \\
\hline & n (\%) & n (\%) \\
\hline \multicolumn{3}{|l|}{ Individual SEP or personal characteristics } \\
\hline \multicolumn{3}{|l|}{ Household occupation } \\
\hline Professional workers $(n=1854)$ & $76(4.1)$ & $1778(95.9)$ \\
\hline Employees $(n=13070)$ & $767(5.9)$ & $12303(94.1)$ \\
\hline Self-employed/Part-time workers/Unemployed $(n=952)$ & $57(6)$ & $895(94)$ \\
\hline \multicolumn{3}{|l|}{ Maternal smoking } \\
\hline Never smoked $(n=15736)$ & $897(5.7)$ & $14839(94.3)$ \\
\hline Ex- or current-smoker $(n=686)$ & $46(6.7)$ & $640(93.3)$ \\
\hline \multicolumn{3}{|l|}{ Maternal alcohol drinking } \\
\hline Non-drinker $(n=15674)$ & $902(5.8)$ & $14772(94.2)$ \\
\hline Drinker $(n=757)$ & $42(5.5)$ & $715(94.5)$ \\
\hline \multicolumn{3}{|l|}{ Paternal smoking } \\
\hline Never smoked $(n=8650)$ & $477(5.5)$ & $8173(94.5)$ \\
\hline Ex or current-smoker $(n=7152)$ & $436(6.1)$ & $6716(93.9)$ \\
\hline \multicolumn{3}{|l|}{ Maternal obesity } \\
\hline Not obese $(n=15215)$ & $855(5.6)$ & $14360(94.4)$ \\
\hline Obese $(n=1348)$ & $91(6.8)$ & $1257(93.2)$ \\
\hline \multicolumn{3}{|l|}{ Maternal diabetes } \\
\hline No diabetes $(n=15983)$ & $913(5.7)$ & $15070(94.3)$ \\
\hline Diabetes $(n=617)$ & $40(6.5)$ & $577(93.5)$ \\
\hline \multicolumn{3}{|l|}{ Maternal hypertension } \\
\hline No hypertension ( $n=15707)$ & $908(5.8)$ & $14799(94.2)$ \\
\hline Hypertension $(n=893)$ & $45(5)$ & $848(95)$ \\
\hline \multicolumn{3}{|l|}{ Area-level SEP at census regions } \\
\hline \multicolumn{3}{|l|}{ Proportion of professional workers } \\
\hline Q1 (affluent) $(n=5453)$ & $182(3.3)$ & $5271(96.7)$ \\
\hline Q2 (middle) $(n=5524)$ & $401(7.3)$ & $5123(92.7)$ \\
\hline Q3 (poor) $(n=5628)$ & $370(6.6)$ & $5258(93.4)$ \\
\hline \multicolumn{3}{|l|}{ Proportion of production or transportation workers } \\
\hline Q1 (affluent) $(n=5406)$ & $84(1.6)$ & $5322(98.4)$ \\
\hline Q2 (middle) $(n=5589)$ & $452(8.1)$ & $5137(91.9)$ \\
\hline Q3 (poor) $(n=5610)$ & $417(7.4)$ & $5193(92.6)$ \\
\hline
\end{tabular}

SEP; socio-economic position.

Indeed, recent reviews suggest that the potential mechanism for the association between air pollution and adverse birth outcomes is impaired placental function (placental oxygen and nutrient transport), in turn brought about by oxidative stress, inflammation, coagulation, impaired endothelial function, and hemodynamic responses $[3,40]$. Diabetes and hypertension can cause preeclampsia, infections, vascular complications, and placental insufficiency during pregnancy [41], which may support the susceptibility of diabetic and hypertensive mothers. The reason why maternal smoking status modified the association between proximity and term LBW may also be related to this mechanism, because smoking is associated with placental insufficiency during pregnancy [41].

Although most air pollution studies used registerbased participants [22-24,42,43], our study participants were maternal-newborn pairs who attended one general hospital with a perinatal center. Not all babies in the 
Table 3 Individual-level SEP within area-level SEP variables $(n=16,615)$

\begin{tabular}{|c|c|c|c|}
\hline & \multicolumn{3}{|c|}{ Area-level SEP at census regions } \\
\hline & Q1 (affluent) & Q2 (middle) & Q3 (poor) \\
\hline & \multicolumn{3}{|c|}{ Proportion of professional workers } \\
\hline \multicolumn{4}{|l|}{ Household occupation } \\
\hline Professional workers $(n=1853)$ & $850(45.9)$ & $545(29.4)$ & $458(24.7)$ \\
\hline Employees $(n=13062)$ & $4103(31.4)$ & $4414(33.8)$ & $4545(34.8)$ \\
\hline \multirow[t]{2}{*}{ Self-employed/Part-time workers/Unemployed $(n=951)$} & $290(30.5)$ & $317(33.3)$ & $344(36.2)$ \\
\hline & \multicolumn{3}{|c|}{ Proportion of production or transportation workers } \\
\hline \multicolumn{4}{|l|}{ Household occupation } \\
\hline Professional workers $(n=1853)$ & $811(43.8)$ & $564(30.4)$ & $478(25.8)$ \\
\hline Employees $(n=13062)$ & $4032(30.9)$ & $4473(34.2)$ & $4557(34.9)$ \\
\hline Self-employed/Part-time workers/Unemployed $(n=951)$ & $355(37.3)$ & $317(33.3)$ & $279(29.3)$ \\
\hline
\end{tabular}

western part of Shizuoka are born in this particular hospital and this hospital-based sampling method may introduce selection bias. However, the proportion of preterm births delivered in this hospital was higher mainly among mothers residing far from the hospital. The proportion of preterm births was $7.4 \%$ among mothers residing close to the hospital (lowest 10th percentile of the distance from the hospital), and $23.4 \%$ among mothers residing far from the hospital (highest 10th percentile of the distance). The hospital is located relatively close to major roads [8], hence this type of selection bias, if it exists, would likely only underestimate the results.

In the present study, we used mothers' proximity to major roads as an index for air pollution exposure, since

Table 4 Odds ratios (ORs) and their $95 \%$ confidence intervals ( $\mathrm{Cls}$ ) between proximity to major roads and preterm births (PTB) or term low birth weight (LBW)

\begin{tabular}{|c|c|c|c|c|}
\hline & Model 1 & Model $2 \ddagger$ & Model $3 \S$ & Model $4^{* *}$ \\
\hline & Crude model & Adjusted model & Individual SEP adjusted & Individual/area-level SEP adjusted \\
\hline & $\overline{\text { OR }(95 \% \mathrm{Cl})}$ & OR $(95 \% \mathrm{Cl})$ & OR $(95 \% \mathrm{Cl})$ & OR $(95 \% \mathrm{Cl})$ \\
\hline \multicolumn{5}{|l|}{ PTB* } \\
\hline \multicolumn{5}{|c|}{ Proximity to major roads } \\
\hline$>200 \mathrm{~m}$ & 1 & 1 & 1 & 1 \\
\hline$\leq 200 \mathrm{~m}$ & $1.6(1.3,1.9)$ & $1.6(1.4,2.0)$ & $1.6(1.3,1.9)$ & $1.5(1.3,1.9)$ \\
\hline \multicolumn{5}{|c|}{ Proximity to major roads } \\
\hline$>200 \mathrm{~m}$ & 1 & 1 & 1 & 1 \\
\hline $50-200 \mathrm{~m}$ & $1.5(1.3,1.9)$ & $1.6(1.3,2.0)$ & $1.6(1.3,1.9)$ & $1.5(1.2,1.8)$ \\
\hline$\leq 50 \mathrm{~m}$ & $2.0(1.2,3.1)$ & $1.9(1.2,3.1)$ & $1.8(1.1,3.0)$ & $1.7(1.0,2.9)$ \\
\hline \multicolumn{5}{|l|}{ Term LBW† } \\
\hline \multicolumn{5}{|c|}{ Proximity to major roads } \\
\hline$>200 \mathrm{~m}$ & 1 & 1 & 1 & 1 \\
\hline$\leq 200 \mathrm{~m}$ & $1.2(1.0,1.6)$ & $1.2(0.9,1.5)$ & $1.2(1.0,1.6)$ & $1.2(0.9,1.6)$ \\
\hline \multicolumn{5}{|c|}{ Proximity to major roads } \\
\hline$>200 \mathrm{~m}$ & 1 & 1 & 1 & 1 \\
\hline $50-200 \mathrm{~m}$ & $1.2(1.0,1.6)$ & $1.2(0.9,1.5)$ & $1.2(0.9,1.6)$ & $1.2(0.9,1.6)$ \\
\hline$\leq 50 \mathrm{~m}$ & $1.3(0.7,2.5)$ & $1.4(0.7,2.8)$ & $1.5(0.8,3.1)$ & $1.5(0.7,3.0)$ \\
\hline
\end{tabular}

*Subjects were all newborns $(n=16,615)$.

†Subjects were newborns at term birth $(n=14,836)$.

$\ddagger$ Adjusted for maternal age, newborn's sex, maternal alcohol consumption, maternal smoking, maternal body mass index, and paternal smoking. Gestational age was also adjusted in the analysis for term LBW.

$\S$ Additionally adjusted for household occupation.

**Additionally adjusted for the proportion of professional workers in the corresponding census.

PTB; preterm birth, LBW; low birth weight, OR; odds ratio, Cl; confidence interval, SEP; socio-economic position. 
Table 5 Odds ratios (ORs) of adverse birth outcomes associated with proximity to major roads ( $\leq 200 \mathrm{~m}$ ) stratified by individual/area-level SEP and parental characteristics

\begin{tabular}{|c|c|c|c|c|}
\hline & \multicolumn{2}{|c|}{ PTB* } & \multicolumn{2}{|c|}{ Term LBW* } \\
\hline & OR $(95 \% \mathrm{Cl})$ & AP $(95 \% \mathrm{Cl})$ & OR $(95 \% \mathrm{Cl})$ & AP $(95 \% \mathrm{Cl})$ \\
\hline \multicolumn{5}{|l|}{ Individual SEP or personal characteristics } \\
\hline \multicolumn{5}{|l|}{ Household occupationt } \\
\hline Professional workers & $1.6(0.8,3.2)$ & - & $1.4(0.6,3.3)$ & - \\
\hline Employees & $1.5(1.2,1.9)$ & $0(-0.6,0.6)$ & $1.1(0.9,1.5)$ & $-0.2(-1.2,0.7)$ \\
\hline Self-employed/Part-time workers/Unemployed & $1.6(0.7,3.5)$ & $0.2(-0.6,1.0)$ & $3.1(1.2,8.2)$ & $0.4(-0.3,1.1)$ \\
\hline \multicolumn{5}{|l|}{ Maternal smokingt } \\
\hline Never smoked & $1.6(1.3,2.0)$ & - & $1.2(0.9,1.5)$ & - \\
\hline Ex- or current-smoker & $0.8(0.3,1.8)$ & $-0.5(-1.6,0.7)$ & $2.4(1.0,6.2)$ & $0.5(0,1.0)$ \\
\hline \multicolumn{5}{|l|}{ Maternal alcohol drinking $\dagger$} \\
\hline Non-drinker & $1.6(1.3,1.9)$ & - & $1.2(1.0,1.6)$ & - \\
\hline Drinker & $1.2(0.4,3.3)$ & $-0.2(-1.3,1.0)$ & $0.7(0.1,3.3)$ & $-0.8(-3.6,1.9)$ \\
\hline \multicolumn{5}{|l|}{ Paternal smoking $†$} \\
\hline Never smoked & $1.7(1.3,2.2)$ & - & $1.2(0.8,1.7)$ & - \\
\hline Ex or current-smoker & $1.4(1.1,1.9)$ & $-0.1(-0.6,0.3)$ & $1.2(0.9,1.8)$ & $-0.1(-0.9,0.8)$ \\
\hline \multicolumn{5}{|l|}{ Maternal obesity $\dagger$} \\
\hline Not obese & $1.6(1.3,2.0)$ & - & $1.2(0.9,1.6)$ & - \\
\hline Obese & $1.3(0.7,2.5)$ & $-0.1(-0.8,0.6)$ & $1.6(0.7,3.6)$ & $0.2(-0.5,0.9)$ \\
\hline \multicolumn{5}{|l|}{ Maternal diabetest } \\
\hline No diabetes & $1.5(1.2,1.8)$ & - & $1.2(0.9,1.6)$ & - \\
\hline Diabetes & $4.4(1.9,10.0)$ & $0.6(0.4,0.9)$ & $1.4(0.3,7.0)$ & $0(-1.5,1.5)$ \\
\hline \multicolumn{5}{|l|}{ Maternal hypertensiont } \\
\hline No hypertension & $1.5(1.2,1.8)$ & - & $1.3(1.0,1.6)$ & - \\
\hline Hypertension & $2.6(1.2,5.4)$ & $0.4(0,0.9)$ & $0.5(0.1,2.5)$ & $-1.1(-4.2,2.0)$ \\
\hline \multicolumn{5}{|l|}{ Area-level SEP at census regions } \\
\hline \multicolumn{5}{|l|}{ Proportion of professional workers§ } \\
\hline Q1 (affluent) & $1.9(1.2,3.0)$ & - & $1.4(0.8,2.6)$ & - \\
\hline Q2 (middle) & $1.6(1.2,2.2)$ & $-0.2(-0.8,0.4)$ & $1.3(0.9,1.9)$ & $0(-0.6,0.6)$ \\
\hline Q3 (poor) & $1.4(1.1,1.9)$ & $-0.2(-0.7,0.4)$ & $1.1(0.7,1.6)$ & $-0.2(-1.0,0.6)$ \\
\hline \multicolumn{5}{|l|}{ Proportion of production or transportation workers§ } \\
\hline Q1 (affluent) & $2.5(1.4,4.4)$ & - & $2.5(1.1,5.5)$ & - \\
\hline Q2 (middle) & $1.2(0.9,1.7)$ & $-0.9(-2.1,0.2)$ & $1.2(0.8,1.8)$ & $-0.9(-2.5,0.7)$ \\
\hline Q3 (poor) & $1.6(1.2,2.2)$ & $-0.3(-0.9,0.4)$ & $1.0(0.7,1.6)$ & $-1.1(-2.9,0.7)$ \\
\hline
\end{tabular}

ORs were estimated against subjects living in the area more than $200 \mathrm{~m}$ from major roads. Proportions attributable to the interaction (AP) between the respective factors and proximity to major roads are also shown.

*Subjects were all newborns $(n=16,615)$ in the analyses for PTB and subjects were newborns at term birth $(n=14,836)$ in the analyses for term LBW. †Adjusted for maternal age, newborn's sex, maternal smoking, maternal alcohol consumption, maternal body mass index, paternal smoking, household occupation, and the proportion of professional workers in the corresponding census. Each confounder was excluded when subjects were stratified by the corresponding variable. Gestational age was also adjusted in the analysis for term LBW.

§Adjusted for maternal age, newborn's sex, maternal smoking, maternal alcohol consumption, maternal body mass index, paternal smoking, and household occupation. Gestational age was also adjusted in the analysis for term LBW.

AP; Proportion attributable to the interaction, Cl; confidence interval, LBW; low birth weight, OR; odds ratio, PTB; preterm birth, SEP; socio-economic position.

air-monitoring stations are limited in their coverage and spatial resolution. However, there is a possibility that proximity to major roads is limited in temporal resolution. Traffic information in this study was obtained from the Road Traffic Census conducted in 2005, and traffic volume data were recorded for only 1 day, during the period from September to November in 2005. Thus, our exposure indicator does not reflect year-to-year or seasonal variations in traffic exposure. Because major roads did not change, the traffic volume would not have varied 
substantially in the year-to-year comparison. The average changes (increase) in daily traffic volume over a 12-hour time period for the whole Shizuoka prefecture were 135 vehicles from 1999 to 2005 and 200 vehicles from 2005 to 2010, respectively [44]. However, our exposure indicator did not provide any indication of seasonal variation.

Exposure misclassification could have occurred because of mothers' movement during pregnancy, as we used maternal residential information at delivery. Therefore, we restricted subjects to those who lived in the western part of Shizuoka prefecture to reduce the possibility of misclassification. Although we could not obtain information about maternal movement, such possible non-differential exposure misclassification between the two categories $(\leq 200 \mathrm{~m}$; > $200 \mathrm{~m})$ would likely have moved effect estimates toward the null [45].

In the present study, we used household occupation as our measure of individual SEP. However, the category was relatively crude. Moreover, we had to combine three categories (Self-employed; Part-time workers; Unemployed) because of limited numbers. Furthermore, we did not have other individual SEP information such as education, income, or wealth [46]. These issues might have affected the observed non-significant interactions between air pollution and adverse birth outcomes in the present study. Additionally, we could not separate mothers who quit smoking before pregnancy (ex-smoker) from mothers who quit smoking during pregnancy, which may have been a potentially confounding factor in the present study.

\section{Conclusions}

The present study demonstrated that air pollution is an independent risk factor for adverse birth outcomes, and lower SEP at both individual and area-levels was associated with the increased occurrence of adverse birth outcomes. Although the interaction was not statistically significant, mothers with lower individual SEP and mothers living in higher SEP regions tended to be susceptible to the adverse effect of air pollution. Moreover, maternal diabetic, hypertensive, and smoking status increased susceptibility to the effect. Further studies are needed to identify mothers vulnerable to air pollution to reduce reproductive adverse outcomes of newborns.

\section{Consent}

According to the ethical guidelines for epidemiological research in Japan, no informed consent from participants was needed because data were existing materials and analyzed anonymously.

\section{Abbreviations}

AP: Proportion attributable to the interaction; BMl: Body mass index; Cl: Confidence interval; GIS: Geographic Information System; LBW: Low birth weight; OR: Odds ratio; SEP: Socio-economic position.

\section{Competing interests}

The authors declare that they have no competing interests.

\section{Authors' contributions}

Study concept and design: TY, SK, ST, HD, IK; Data collection: HN, TM; Data handling: TY, SK; Analysis: TY; Interpretation of data: TY, SK, ST, HD, IK; Drafting of the manuscript: TY, IK; Critical revision of the manuscript: HN, SK, ST, TM, HD; Study supervision: IK. All authors read and approved the final manuscript.

\section{Acknowledgments}

We appreciate the contributions of the staff at Seirei Hamamatsu General Hospital in maintaining the perinatal dataset. The software in this study was supported by the Higher Education Grant Program of ESRI Japan Corp. This work was supported in part by Grant-in-Aid for Scientific Research (C) from the Ministry of Education, Culture, Sports, Science and Technology (No 24510033) and Grants for Environmental Research Projects from the Sumitomo Foundation.

\section{Author details}

'Department of Human Ecology, Okayama University Graduate School of Environmental and Life Science, 1-1-1 Tsushima-naka, Kita-ku, Okayama 700-8530, Japan. ${ }^{2}$ Department of Obstetrics, Seirei Hamamatsu General Hospital, 2-12-12 Sumiyoshi, Naka-ku, Hamamatsu, Shizuoka 430-8558, Japan. ${ }^{3}$ Department of Public Health and Health Policy, Institute of Biomedical \& Health Sciences, Hiroshima University, 1-2-3 Kasumi, Minami-ku, Hiroshima 734-8551, Japan. ${ }^{4}$ Department of Epidemiology, Okayama University Graduate School of Medicine, Dentistry and Pharmaceutical Sciences, 2-5-1 Shikata-cho, Kita-ku, Okayama 700-8558, Japan. ${ }^{5}$ Department of Society, Human Development, and Health, Harvard School of Public Health, 677 Huntington Ave, Boston, MA 02115, USA.

Received: 20 December 2012 Accepted: 8 April 2013

Published: 18 April 2013

\section{References}

1. Glinianaia SV, Rankin J, Bell R, Pless-Mulloli T, Howel D: Particulate air pollution and fetal health: a systematic review of the epidemiologic evidence. Epidemiology 2004, 15:36-45.

2. Maisonet M, Correa A, Misra D, Jaakkola JJ: A review of the literature on the effects of ambient air pollution on fetal growth. Environ Res 2004, 95:106-115

3. Slama R, Darrow L, Parker J, Woodruff TJ, Strickland M, Nieuwenhuijsen M, Glinianaia S, Hoggatt KJ, Kannan S, Hurley F, Kalinka J, Sram R, Brauer M, Wilhelm M, Heinrich J, Ritz B: Meeting report: atmospheric pollution and human reproduction. Environ Health Perspect 2008, 116:791-798.

4. Sram RJ, Binkova B, Dejmek J, Bobak M: Ambient air pollution and pregnancy outcomes: a review of the literature. Environ Health Perspect 2005, 113:375-382.

5. Ghosh JK, Wilhelm M, Su J, Goldberg D, Cockburn M, Jerrett M, Ritz B: Assessing the influence of traffic-related air pollution on risk of term low birth weight on the basis of land-use-based regression models and measures of air toxics. Am J Epidemiol 2012, 175:1262-1274.

6. Shah PS, Balkhair T: Air pollution and birth outcomes: a systematic review. Environ Int 2011, 37:498-516.

7. Stieb DM, Chen L, Eshoul M, Judek S: Ambient air pollution, birth weight and preterm birth: a systematic review and meta-analysis. Environ Res 2012, 117:100-111.

8. Yorifuji T, Naruse H, Kashima S, Ohki S, Murakoshi T, Takao S, Tsuda T, Doi H: Residential proximity to major roads and preterm births. Epidemiology 2011, 22:74-80.

9. Brook RD, Rajagopalan S, Pope CA 3rd, Brook JR, Bhatnagar A, Diez-Roux AV, Holguin F, Hong Y, Luepker RV, Mittleman MA, Peters A, Siscovick D, Smith SC Jr, Whitsel L, Kaufman JD: Particulate matter air pollution and cardiovascular disease: An update to the scientific statement from the American Heart Association. Circulation 2010, 121:2331-2378.

10. Sacks JD, Stanek LW, Luben TJ, Johns DO, Buckley BJ, Brown JS, Ross M: Particulate matter-induced health effects: who is susceptible? Environ Health Perspect 2011, 119:446-454.

11. Woodruff TJ, Parker JD, Darrow LA, Slama R, Bell ML, Choi H, Glinianaia S, Hoggatt K, Karr CJ, Lobdell DT, Wilhelm M: Methodological issues in 
studies of air pollution and reproductive health. Environ Res 2009, 109:311-320.

12. O'Neill MS, Jerrett M, Kawachi I, Levy II, Cohen AJ, Gouveia N, Wilkinson P, Fletcher T, Cifuentes L, Schwartz J: Health, wealth, and air pollution: advancing theory and methods. Environ Health Perspect 2003, 111:1861-1870.

13. Bell ML, Dominici F: Effect modification by community characteristics on the short-term effects of ozone exposure and mortality in 98 US communities. Am J Epidemiol 2008, 167:986-997.

14. Forastiere F, Stafoggia M, Tasco C, Picciotto S, Agabiti N, Cesaroni G, Perucci CA: Socioeconomic status, particulate air pollution, and daily mortality: differential exposure or differential susceptibility. Am J Ind Med 2007, 50:208-216

15. Martins MC, Fatigati FL, Vespoli TC, Martins LC, Pereira LA, Martins MA, Saldiva $\mathrm{PH}$, Braga $\mathrm{AL}$ : Influence of socioeconomic conditions on air pollution adverse health effects in elderly people: an analysis of six regions in Sao Paulo, Brazil. J Epidemiol Community Health 2004, 58:41-46.

16. Samet JM, Dominici F, Curriero FC, Coursac I, Zeger SL: Fine particulate air pollution and mortality in 20 U.S. cities, 1987-1994. N Engl J Med 2000, 343:1742-1749.

17. Zanobetti A, Schwartz J, Dockery DW: Airborne particles are a risk factor for hospital admissions for heart and lung disease. Environ Health Perspect 2000, 108:1071-1077.

18. Hoek G, Brunekreef B, Goldbohm S, Fischer P, van den Brandt PA: Association between mortality and indicators of traffic-related air pollution in the Netherlands: a cohort study. Lancet 2002, 360:1203-1209.

19. Medina-Ramon M, Schwartz J: Who is more vulnerable to die from ozone air pollution? Epidemiology 2008, 19:672-679.

20. Pope CA 3rd, Burnett RT, Thun MJ, Calle EE, Krewski D, Ito K, Thurston GD: Lung cancer, cardiopulmonary mortality, and long-term exposure to fine particulate air pollution. JAMA 2002, 287:1132-1141.

21. Zeka A, Zanobetti A, Schwartz J: Individual-level modifiers of the effects of particulate matter on daily mortality. Am J Epidemiol 2006, 163:849-859.

22. Genereux M, Auger N, Goneau M, Daniel M: Neighbourhood socioeconomic status, maternal education and adverse birth outcomes among mothers living near highways. J Epidemiol Community Health 2008, 62:695-700.

23. Ponce NA, Hoggatt KJ, Wilhelm M, Ritz B: Preterm birth: the interaction of traffic-related air pollution with economic hardship in Los Angeles neighborhoods. Am J Epidemiol 2005, 162:140-148.

24. Wilhelm M, Ritz B: Residential proximity to traffic and adverse birth outcomes in Los Angeles county, California, 1994-1996. Environ Health Perspect 2003, 111:207-216.

25. Yi O, Kim H, Ha E: Does area level socioeconomic status modify the effects of PM(10) on preterm delivery? Environ Res 2010, 110:55-61.

26. Rich DQ, Demissie K, Lu SE, Kamat L, Wartenberg D, Rhoads GG: Ambient air pollutant concentrations during pregnancy and the risk of fetal growth restriction. J Epidemiol Community Health 2009, 63:488-496.

27. Yorifuji T, Naruse H, Kashima S, Murakoshi T, Tsuda T, Doi H, Kawachi I: Residential proximity to major roads and placenta/birth weight ratio. Sci Total Environ 2012, 414:98-102.

28. Hart JE, Laden F, Puett RC, Costenbader KH, Karlson EW: Exposure to traffic pollution and increased risk of rheumatoid arthritis. Environ Health Perspect 2009, 117:1065-1069.

29. Jerrett M, Arain A, Kanaroglou P, Beckerman B, Potoglou D, Sahsuvaroglu T, Morrison J, Giovis C: A review and evaluation of intraurban air pollution exposure models. J Expo Anal Environ Epidemiol 2005, 15:185-204.

30. Nitta H, Sato T, Nakai S, Maeda K, Aoki S, Ono M: Respiratory health associated with exposure to automobile exhaust. I. Results of cross-sectional studies in 1979, 1982, and 1983. Arch Environ Health 1993, 48:53-58.

31. Ono M: Pollution around a road (in Japanese): from Introduction of Environmental Health edited by Koizumi, A. and Murakami, M. Nihonhyouronnsha: Tokyo; 1990.

32. Kashima S, Yorifuji T, Tsuda T, Doi H: Application of land use regression to regulatory air quality data in Japan. Sci Total Environ 2009, 407:3055-3062.

33. Ryan PH, LeMasters GK: A review of land-use regression models for characterizing intraurban air pollution exposure. Inhal Toxicol 2007, 19(Suppl 1):127-133.

34. Knol MJ, VanderWeele TJ: Recommendations for presenting analyses of effect modification and interaction. Int J Epidemiol 2012, 41:514-520.

35. Hosmer DW, Lemeshow S: Confidence interval estimation of interaction. Epidemiology 1992, 3:452-456.
36. Sugiri $D$, Ranft $U$, Schikowski T, Kramer $U$ : The influence of large-scale airborne particle decline and traffic-related exposure on children's lung function. Environ Health Perspect 2006, 114:282-288.

37. Morgen CS, Bjork C, Andersen PK, Mortensen LH, Nybo Andersen AM: Socioeconomic position and the risk of preterm birth-a study within the Danish National Birth Cohort. Int J Epidemiol 2008, 37:1109-1120.

38. Kagamimori S, Gaina A, Nasermoaddeli A: Socioeconomic status and health in the Japanese population. Soc Sci Med 2009, 68:2152-2160.

39. Baja ES, Schwartz JD, Wellenius GA, Coull BA, Zanobetti A, Vokonas PS, Suh $\mathrm{HH}$ : Traffic-related air pollution and QT interval: modification by diabetes, obesity, and oxidative stress gene polymorphisms in the normative aging study. Environ Health Perspect 2010, 118:840-846.

40. Kannan S, Misra DP, Dvonch JT, Krishnakumar A: Exposures to airborne particulate matter and adverse perinatal outcomes: a biologically plausible mechanistic framework for exploring potential effect modification by nutrition. Environ Health Perspect 2006, 114:1636-1642.

41. Cunningham FG: Williams JW (Eds): Williams obstetrics, 23rd edition. New York: McGraw-Hill Medical; 2010.

42. Brauer M, Lencar C, Tamburic L, Koehoorn M, Demers P, Karr C: A cohort study of traffic-related air pollution impacts on birth outcomes. Environ Health Perspect 2008, 116:680-686.

43. Leem JH, Kaplan BM, Shim YK, Pohl HR, Gotway CA, Bullard SM, Rogers JF, Smith MM, Tylenda CA: Exposures to air pollutants during pregnancy and preterm delivery. Environ Health Perspect 2006, 114:905-910.

44. Road Traffic Census. http://www.cbr.mlit.go.jp/road/census/.

45. Szklo M, Nieto FJ: pidemiology : beyond the basics. 2nd edition. Sudbury, Mass: Jones and Bartlett Publishers; 2007.

46. Oakes JM, Kaufman JS: Methods in social epidemiology. 1st edition. San Francisco, CA: Jossey-Bass; 2006.

\section{doi:10.1186/1476-069X-12-34}

Cite this article as: Yorifuji et al:: Residential proximity to major roads and adverse birth outcomes: a hospital-based study. Environmental Health 2013 12:34.

\section{Submit your next manuscript to BioMed Central and take full advantage of:}

- Convenient online submission

- Thorough peer review

- No space constraints or color figure charges

- Immediate publication on acceptance

- Inclusion in PubMed, CAS, Scopus and Google Scholar

- Research which is freely available for redistribution

Submit your manuscript at www.biomedcentral.com/submit
C BioMed Central 